

Saggital MRI (T1 weighted) showing prominent vermal hypoplasia of the cerebellum and enlarged cerebellomedullary cistern.

Tendon reflexes were elicited at a low level and ankle jerks were absent. There were no pyramidal tract signs. A finger to nose test was normal, whereas a heel to shin test was inaccurate. The patient could not rise from the prone position without help. His gait was broad based and ataxic, and tandem gait was not possible. There was no Romberg's sign. Sensation for touch and pain was preserved. Position and vibration sense could not be tested. Electromyography ( $M$ tibialis anterior; $M$ extensor digitorum brevis) and nerve conduction studies (tibial, peroneal and median nerve) gave normal results. Formal testing showed an IQ below 50 on the Columbia mental maturity scale, but an IQ of 90 on the block design test of the revised Wechsler adult intelligence scale. Incipient lenticular opacities were seen on slit lamp examination. Visual evoked potentials were normal. Audiometric examination and acoustic evoked potentials disclosed bilateral combined hearing loss. An EEG disclosed alpha rhythms without seizure activity. Electrocardiography and echocardiography were without abnormalities. Brain MRI showed cerebral atrophy, hypoplasia of the lower vermis, and an enlarged cerebellomedullary cistern (figure). Radiography showed coxa valga deformity with degenerative arthritis in both hips and dysostosis multiplex in his spine and pelvis. Urinary examination showed an abnormal pattern of oligosaccharide excretion; $\alpha$-mannosidase was very low in serum $(0.0268 \mathrm{mU} / \mathrm{ml}$; normal: $0 \cdot 109-1 \cdot 173)$. Other routine laboratory investigations, including measurement of immunoglobulins, gave normal results.

Our patient does not fit the conventional classification, as features of type I (early onset; recurrent infections) and type II $\alpha$ mannosidosis (prolonged survival) were found. Interestingly, no vacuolated lymphocytes could be found in his or his mother's blood at follow up on three different occasions. The neuropsychological results are best interpreted as the dissociation between preserved visuospatial abilities and impaired language due to hearing difficulties. Stable scores for general intelligence and visuospatial abilities over time argue against a cognitive decline in $\alpha$-mannosidosis. Ataxia was progressive also in other cases of adult $\alpha$ mannosidosis. ${ }^{5}$ Cerebellar signs in this condition may be the consequence of precocious age-related attrition in cerebellar neurons due to prior storage of compounds containing mannose.

We are grateful to Professor H-D Weiß, who kindly permitted publication of the MRI.

$S$ NIEMANN $M$ BECK

G SEIDEL

J SPRANGER Klinik für Neurologie,

Medizinische Universität zu Lübeck, D-23538 Lübeck, Germany

Correspondence to: Dr Peter Vieregge.

Dietemann JL, Filippi de la Palavesa MM, Tranchant C, Kastler B. MR findings in Tranchant C, Kastler B. MR findings in
mannosidosis. Neuroradiology 1990;32: 485-7.

2 Bennet JK, Dembure PP, Elsas LJ. Clinical and biochemical analysis of two families with Genet 1995;55:21-6.

3 Spranger J, Wiedemann HR, Tolksdorf $M$, Graucob E, Caesar R. Lipomucopolysaccharidose. Eine neue Speicherkrankheit. $Z$ Kinderhkd 1968;103:285-306. ographic features of mannosidosis. Radiology 1976;119:401-7.

5 Patton MA, Barnes IC, Young ID, Harper PS, Pennock CA. Mannosidosis in two brothers: prolonged survival in the severe phenotype. prolonged survival in the $1982 ; 22: 284-9$.

\section{Electromyography of the serratus anterior and subscapularis muscles: description of a technique}

Weakness of the muscles of the shoulder girdle, especially of the serratus anterior muscle, results in winging of the scapula and is most often caused by neuralgic amyotrophy or degenerative myopathies-for example, facioscapulohumeral muscular dystrophy. Several techniques have been proposed for needle EMG of the serratus anterior muscle: The needle can be inserted in the muscle superficially to the fourth to sixth rib in the medial or posterior axillary line. ${ }^{1-3}$ In our experience, this technique usually samples only a few muscle fibres and there is a risk of inducing a pneumothorax by penetrating the intercostal space. Delagi et $a l^{4}$ suggested inserting the needle just lateral to the infetype I and type II mannosidosis. Am $\mathcal{f}$ Med

4 Spranger J, Gehler J, Cantz $M$. The radi-

rior angle of the scapula. If the needle is inserted too superficially, the EMG is recorded from the latissimus dorsi muscle. If the insertion is too cranial the teres major muscle is encountered. As winging of the scapula is the most frequent reason for examination of the serratus anterior muscle, EMG can be most easily performed at the medial border of the scapula while the patient is standing and pressing his anteriorly extended arm against a wall. This position also allows EMG examination of the subscapularis muscle, which contributes to shoulder stability and internal rotation of the humerus (see figure). Needle EMG of this muscle is usually performed using wire electrodes inserted in the posterior axillary line with the subject in a supine position and the arm held in an abducted and externally rotated position. ${ }^{5}$ If the needle is inserted too superficially, it will be in the rhomboideus major muscle, which also inserts at the medial border of the scapula. Active adduction of the scapula (rhomboideus muscle) and of the humerus (subscapular muscle) allows differentiation of these muscles. In patients with facioscapulohumeral muscular dystrophy, we found more abnormal EMG activity in the subscapular muscle. Thus the investigation of this muscle seems to be of some diagnostic value in patients with winging of the scapula.

CARI D REIMERS MATHIAS KUNKEL Clinical Neurophysiology, Department of Clinical Neurophysiology,
ARNO SIEVER Department of Neurology HERBERT KOLENDA Department of Neurosurgery, Georg-August University, Göttingen, Germany

Correspondence to: Dr Carl D Reimers, Department of Clinical Neurophysiology, Georg-AugustUniversity, Robert-Koch-Strasse 40, D-37075 Göttingen, Germany.

1 Alexandre $\mathrm{JH}$, Lacert $\mathrm{P}$, Hamonet C. Exploration électromyographique du muscle du grand dentelé. Rev Neurol 1969;120: du grand.

2 Büll ML, Vitti $M$, de Freitas V. Electromyographic study of the trapezius (pars superior) and serratus anterior (pars inferior) muscles in free movements of the shoulder. Electromyogr Clin Neurophysiol 1989;29: 119-25.

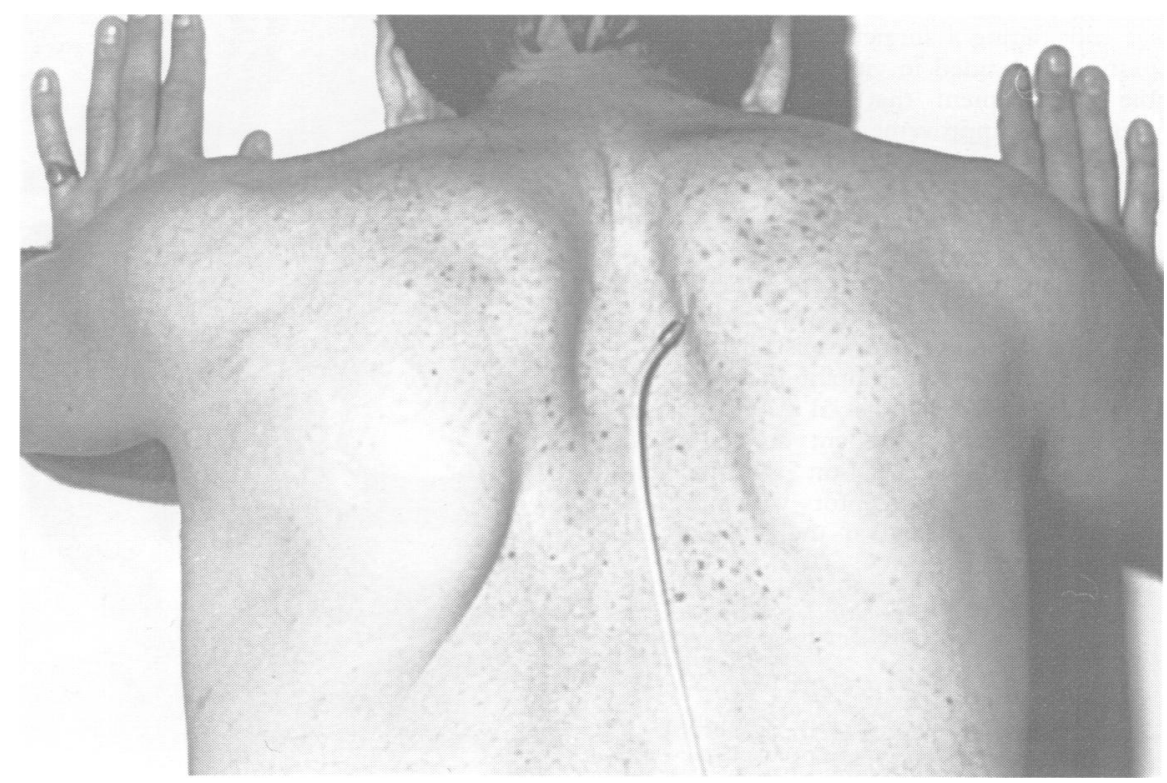

Needle EMG of the subscapular muscle with the upright standing patient pressing his hands against a wall. 
3 Ludin H-P. Praktische Elektromyographie 4th ed. Stuttgart: Enke, 1993:21.

4 Delagi EF, Perotto A, Iazzetti J, Morrison D. Anatomic guide for the electromyographer. The limbs. Springfield, Ill: Thomas, 1981:106-7.

5 Nemeth G, Kronberg M, Brostrom LA Electromyogram (EMG) recordings from the subscapularis muscle: description of a technique. F Orthop Res 1990;8:151-3.

\section{Hemifacial spasm: treatment with pizo- tifen}

The surgical treatment of hemifacial spasm has recently been reported in this fournal. ${ }^{1} \mathrm{I}$ report the beneficial effects of pizotifen, a 5HT receptor antagonist, in two patients with hemifacial spasm. The original observation was entirely by chance as the drug was introduced to help a patient with frequent migraine attacks.

Patient 1, a 43 year woman pharmacist, had an eight month history of right hemifacial spasm after the removal of a meibomian cyst from the lower eyelid in December 1994. There was also a background history of migraine headache fulfilling the criteria for the diagnosis as defined by The International Headache Society. Pizotifen ( $1 \mathrm{mg}$ a day), was introduced by her general practitioner in an attempt to reduce the frequency of the migraine attacks. There was a rapid and consistent benefit from the point of view of the hemifacial spasm, although there seemed to be no reduction in the migraine attacks. The patient stopped the pizotifen and within 36 hours, the facial spasms returned. Several more trials of treatment, followed by stopping it, were undertaken, all with the same result. On continued pizotifen treatment, the benefit on her hemifacial spasm has been maintained.

Patient 2, a 52 year old woman clerk presented with a very long history of left hemifacial spasm. She had undergone various non-surgical treatments previously, including botulinum toxin, with variable benefit. There was also a background history of frontal headaches. These were more in keeping with a diagnosis of a tension type headache syndrome. In view of the previous case, pizotifen ( $1.5 \mathrm{mg}$ at night), was introduced and there was very good improvement in the hemifacial spasm, although it was not completely abolished. The patient was considering a surgical approach for the spasm but decided in view of the considerable improvement that she would await events. The improvement has persisted for more than three months on continued pizotifen.

Considerable caution must obviously apply to the finding of just two patients benefiting from pizotifen treatment in hemifacial spasm. It is interesting, however, that the first patient, being a pharmacist, had undertaken several trials of stopping the treatment with the return of hemifacial spasm, only to see consistent improvement on restarting. The mechanism of action is unknown antagonising $5 \mathrm{HT} 1$ receptors with pizotifen might inhibit neurons at the level of the VIIth nerve nucleus. rey Neurology Research Unit, The Royal Surrey County Hospital, Guildford, Surrey GU2 5XX, UK

1 Illingworth RD, Porter DG, Jakubowski J Hemifacial spasm: a prospective long term follow up of 83 cases treated by microvascular decompression at two neurourgical cen tres in the United Kingdom. $\mathcal{f}$ Neurol Neurosurg Psychiatry 1996;60:72-7.
Orthostatic hypotension caused by a localised dorsal medullary tumour

Orthostatic hypotension is the most dramatic circulatory expression of autonomic failure. To control blood pressure, an intact baroreflex loop is necessary. ${ }^{12}$ In 1984, Hsu et al reported three cases of brainstem tumours that compromised baroreflex function. ${ }^{3}$ Here, we describe a patient who presented with severe orthostatic hypotension, respiratory failure, and bulbar palsy associated with a medullary tumour. We examined the autonomic function of the patient. This case is unique, because of its rarity and diagnostic aspects.

A 54 year old man was admitted to Anjio Kosei Hospital on 21 April 1994 because of hoarseness, anorexia, dysphagia, and postural dizziness. These symptoms first appeared in March 1994. He had a history of ankylosing spondylitis and acute myocardial infarction diagnosed at the ages of 26 and 51 years, respectively. His general examination was unremarkable except for ankylosis of the spine and a cachectic appearance. Neurological examination disclosed a nasal voice, atrophy of the tongue, and absence of the gag reflex bilaterally. Motor, sensory, and cerebellar functions were normal except for a mild proximal weakness of the limbs, probably from disuse. His gait was normal, and he could use a pair of chopsticks. The deep tendon reflexes were normal. There were no pyramidal signs. His blood pressure decreased from $160 / 100$ to $80 / 60 \mathrm{~mm} \mathrm{Hg}$ when he rose from a supine to a seated position, whereas his heart rate remained unchanged. $\mathrm{He}$ had no urinary dysfunction.

A plain cranial CT disclosed no apparent

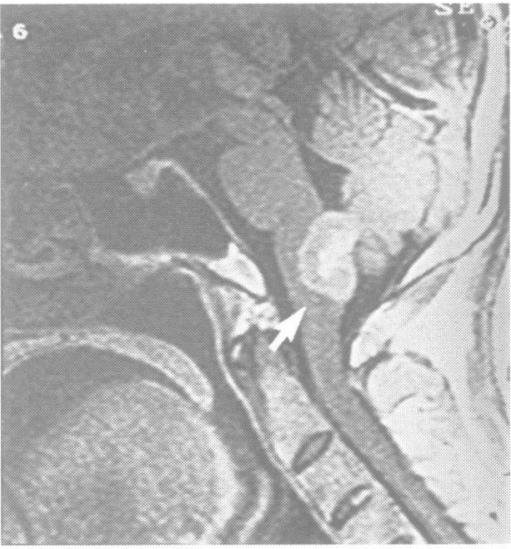

(A)

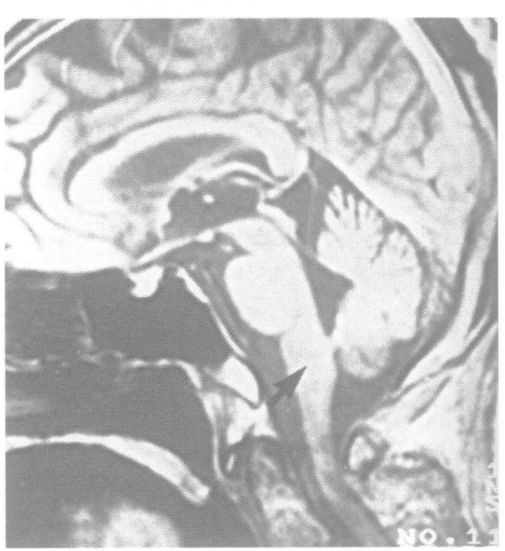

(A) Enhanced MRI (26 May 1994) shows a circumscribed brain tumour located in the dorsal (A) Enhanced MRI (26 May 1994) shows a circumscribed brain tumour located in the dorsal decrease in tumour size after irradiation therapy. Only a few small enhanced lesions are visible.
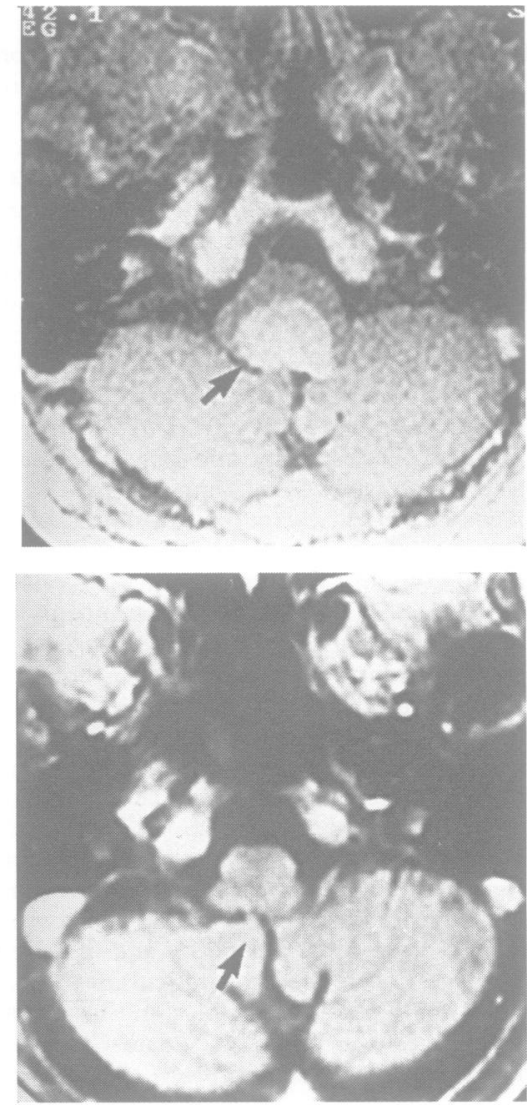

lesion. His CSF contained 38 cells per $\mathrm{mm}^{3}$ and the protein concentration was $90 \mathrm{mg} / \mathrm{dl}$ Repeated cytological analysis of the CSF disclosed no malignant cells. On 26 May, enhanced MRI showed a circumscribed brain tumour located in the dorsal medulla with involvement of the obex. Two additional smaller tumours also were found in the right cerebellum and in the right lateral periventricle (figure). No lesions in the spinal cord or peripheral nerves were noted. Nerve conduction studies of the limbs were normal. Repeated examinations of the whole body failed to disclose any evidence of a primary tumour. The intracranial tumour was considered to be a malignant lymphoma based on its radiosensitivity and neuroimaging

After his admission, the patient's postural frequency of syncopal attacks increased. An episode of respiratory arrest after syncope occurred during defecation on the morning of 7 June. He was unable to breath spontaneously, and showed clouding of consciousness. However, he could respond voluntarily to some orders. Assisted ventilation was performed for the next two months. Irradiation therapy applied to his whole brain ( $40 \mathrm{~Gy}$ ) and to the medullary lesion $(14.4 \mathrm{~Gy})$ was performed from 6 June to 19 July. On 20 October, only small enhanced spots were seen on an MRI with contrast. His respirawas able to breath without aid; however, his episodic orthostatic hypotension and bulbar deficits remained. Both sympathomimetic and mineralocorticoid agents given via gastric tube were ineffective in treating his orthostatic hypotension. The use of suppor stockings to prevent blood pooling in his 